\title{
VOCABULARY MASTERY STRATEGIES USED BY INDONESIAN EXTENSIVE READING LEARNERS
}

\author{
Listyani, Onie Pradina \\ Universitas Kristen Satya Wacana
}

\begin{abstract}
Vocabulary mastery is a key aspect of foreign language leaning. Various methods can be used to improve vocabulary mastery. This present study was conducted to find out what strategies the learners of the Extensive Reading Course used in mastering the vocabulary in an English Language Education Program at a private university in Central Java, Indonesia, based on the Schmitt's (2000) theory. The strategies discussed in this study are the determination, metacognitive, cognitive, memory and social strategy. In this study, a qualitative research design was applied to collect the data using questionnaire with open-ended questions. There were fifty-six participants of three Extensive Reading classes for this study. The result of the study showed that the determination strategy was the most preferable.Most of the participants used that strategy to enrich their vocabulary, while the social strategy was the least used. It was found that most of Extensive Reading learners used determination strategies to mastery vocabulary
\end{abstract}

Key words: reading, extensive reading, vocabulary, vocabulary learning strategy.

\section{INRODUCTION}

It is well known that the relations between reading and vocabulary are widely accepted. There have been many which support the proposition that time and adequate opportunity to read result in a growth of vocabulary (International Literacy Association [ILA], 2019). In fact, many learners still do not master vocabulary quite well, so that they find difficulties in understanding the text and grabbing the main idea of every paragraph. Therefore, learners need appropriate strategies to master essential vocabulary. Some learners master the language successfully while others fail. It may have something to do with some learning strategies (He, 2010). Hence, learners should select and apply their own strategy for mastering vocabulary. Learners may use strategies that suit their study goal in mastering vocabulary. Therefore, learners' strategies are another crucial factor that can affect foreign language acquisition (He, 2010).

In an English Language Education Program (ELEP), ata private university in Central Java, Indonesia, reading courses were divided into two sub-courses; Extensive Reading and Critical Reading. The first course learners need to take is the Extensive Reading course. In order to pass the Extensive Reading course, learners need to read at least one thousand two hundred and fifty pages. Every week learners are required to read at least six books. By identifying the learners' strategies in mastering vocabulary of L2 in the Extensive Reading class, we can obtain a clearer picture and better understanding of learners' vocabulary learning and thus we can prepare a better plan to help the struggling learners. 
The purpose of this study was therefore to find out what strategies the learners of Extensive Readingcourse used in mastering vocabulary. There was only one question in this study: What strategies did learners of Extensive Reading course use in mastering vocabulary?The result of this study was expected to give benefit to Extensive Reading learners in mastering vocabulary. This study was also aimed at showing that every learner has used his/her own strategy. The background of this study would be discussed in detail in the literature review.

\section{Reading Skills}

Reading is one of the basic skills to learn a foreign language. As seen in a research by Smith it can be inferred that reading was also an important skill to learn a foreign language. Smith (1978) stated that reading involved a number of general skills that cannot be ignored. Beyond reading, learners get information and knowledge that are applicable in daily life. It can be assumed that reading text, reading the texts helps learners to enhance their brain exercise i.e. memorizing and concentrating. Above all, learners can enrich their vocabulary by reading. The nature of incremental vocabulary acquisition adds difficulties to incidental vocabulary learning. The later is a 'by-product' of any language learning activity, including reading (Sonbul\& Schmitt, 2010). Furthermore, written language is very different from conversational speech. More sophisticated language in the written text involves more complex grammar than daily interactions (Hueggtig\& Pickering, 2019).

Although reading is important for literature development, many learners are still not aware of its importance. Learners may find reading boring, time consuming, and tiring. Learners with lower reading ability tend to think that reading is serious, a difficult process, requiring hard work and disciplined effort (Elley, 1992). On the other hand, learners with higher reading ability tend to take a meaning-centered approach (Devine, 1984 as cited in Day \& Bamford, 1998, p. 7). This is the difference between good and poor learners in terms of reading ability. The difference also lies in in the amount of time spent on reading. In short, because reading is important and beneficial, learners are expected to get accustomed to read a lot in their effort to gain linguistic proficiency and good reading ability.

\section{Extensive Reading}

Extensive reading is one of the basic activities in reading courses. It may help learners to improve their general reading skill. Learners may start with basicintermediate level of reading materials, so they will enjoy the process of the reading. The texts that are used are relatively easy for the learners to understand, with only few new, strange words (Watkins, 2018). In the long run, learners may improve their speed and fluency in reading and thus they will naturally attain high level of linguistic proficiency. Furthermore, extensive reading may help learners to enrich themselves with extended vocabulary and grammar exercise. It is generally accepted that vocabulary is one of the most vital aspects of learning English a foreign language (EFL), and extensive reading can lead learners to good vocabulary growth (Teng, 2015). Providing time for extensive readingis therefore 
essential for it is one of the most useful vocabulary learning strategies available (Lin, 2016). Extensive reading has also been seen beneficial in terms of writing development and grammar acquisition (Watkins, 2018). Reading a lot through extensive reading course allows leaners to enhance an awareness of collocations and lexical phrases, and it provides opportunities to examine grammar in context so learners can deepen their understanding about the usage of grammar.

Today, extensive reading is recognized as one of four ways of reading. The other three are skimming, scanning, and intensive reading (Day \& Bamford, 1998). The literature clearly demonstrates that extensive reading gives great benefits in both L1 and L2 contexts (ILA, 2019). Moreover, extensive reading is influential not only on vocabulary building and grammar mastery, but also on colloquial fluency. This means that extensive reading in a foreign language context could be used to support the broader curriculum objectives (Cambridge University Press, 2019).

\section{Vocabulary in Second Language Learning}

In learning a foreign language, vocabulary has an important influence to build up learners' communication skill. The essential role that vocabulary plays in language competence and literacy development has been acknowledged in language acquisition studies, especially within the domain of foreign language acquisition research (Lin, 2016). Besides, vocabulary has essential effects on reading, speaking, writing, and listening skills. In reading the text, learners are able to comprehend the main ideas and content of the text more rapidly if they have good mastery of vocabulary. In writing, good mastery vocabulary helps learners to produce more sensible sentences using correct grammar. In listening and speaking, learners' adequate mastery of vocabulary will enable them to make sensible sentences to transfer their ideas during communication, and so they can understand ideas from others. In fact, vocabulary mastery is a must in learning foreign language. Alqahtani (2015) mentioned that vocabulary mastery is often regarded as a critical tool for foreign language learners. Furthermore, Asgari and Mastapha (2010) were in line with Alqahtani, mentioning that in learning any language, vocabulary is the central point of acquisition. It has been recognized as an important aspect in language use.Insufficient vocabulary knowledge of the learners will lead to difficulties in second language learning.

The role of vocabulary in literature has been discussed and studied. According to Easterbrook (2013), vocabulary is discussed first because it is the basic necessity of learning the foreign language and the primary knowledge that the EFL need to have. Vocabulary mastery is a key aspect of foreign language learning (Easterbook, 2013). Moreover, Arndt and Woore (2018) advised that vocabulary knowledge is an essential requirement in comprehending and producing a foreign language. Researchers have agreed that lexical knowledge is complex and it contains more than just form-meaning connections (Arndt \&Woore, 2018). That is why learners may only recognize a word form, but do not know its associated meaning. However, after passing through various phases of partial word 
knowledge, they may be able to produce the spoken and written forms and also use the word appropriately in terms of grammar, semantics, and collocations.

\section{Vocabulary Learning Strategies}

Strategy in this research is referred to as method applied by learners in attempt to achieve their goals. Vocabulary learning strategies (VLSs) is known as the step taken by language learner to obtain new words. Easterbrook (2013) claimed that language learning is not viewed as a single factor activity. In a study conducted by Schmitt (2000), VLSs were classified into five categories; they are determination, social, memory, cognitive and metacognitive strategy. The followings are the differences and the definitions of those strategies.

Determination strategy is an individual learning strategy. This strategy consists of analyzing part of speech, affixes, roots, and available pictures or gestures, using the meaning from textual context, and using dictionaries of both bilingual and monolingual (Schmitt, 2000). The next is social strategy, which is referred to as a strategy used by learners when they learn new words through interaction with others. Learners are allowed to get involved in interaction with their peers and the strategy assists them to learn from each other, such as observing the classmates and asking the teacher about word meanings and the semantics (Schmitt, 2000).Next is Memory strategy, which is a type of strategy in which learners link their learning of new words to mental processing by associating their existing or background knowledge with the new words. Memory strategycovers learning activities such as connecting word to a previous personal experience, associating the word with its coordinate, using semantic maps, imaging word forms, grouping word together to study them, studying the spelling of a word, saying new word aloud when studying and using physical action when learning a word (Schmitt, 2000).

Cognitive strategy is a kind of strategy that does not engage learners in mental processing; rather it is considered a mechanical means. It consists of verbal repetition, written repetition, word list, putting English labels on physical object and keeping vocabulary notebook (Schmitt, 2000).Metacognitive strategy is referred to as a strategy related to processes involved in monitoring, decisionmaking, and evaluation of one's progress. This strategy helps learners in determining appropriate VLSs. Metacognitive strategy includes using English language media (songs, movies, news and some others), using space of word practice, testing oneself with word tests, skipping or pass new word, continuing to study new word over time (Schmitt, 2000).

In this study, the researchers used Schmitt's VLSs, considering that his strategy is more specific to be used and applied as base theory for this study. Types of strategies the learners are going to apply do not matter, as long as the strategies are appropriate and applicable in understanding the texts and procuring necessary vocabulary. Asgari and Mustapha (2011) said that acquiring a foreign language involves different areas like motivation, learners' needs, learning environment, learning strategies and language awareness. 


\section{Previous Studies}

There were not many researchers that discussed about this topic before. The previous studies have only discussed much about vocabulary learning strategy for EFL. The main benefit of this study is discussing in details about strategies the learners of Extensive Reading used in mastering vocabulary.

One of the researchers was Dwitama (2015). He conducted research about the types of strategies learners used in learning new vocabulary through reading. The aim of the study is to find out the vocabulary learning strategies used by the FLA (Faculty of Language and Arts) learners in Extensive Reading class. The study was conducted in a private university, in Central Java, Indonesia. The participants of the study were 100 FLL learners who have passed the Extensive Reading course. The study used questionnaire with closed-ended questions to collect the data. The result of the study showed that the majority of FLL learners were in favor of using determination strategy in learning process. What made this study different from the one made by Dwitama were the participants. Dwitama took learners that had passed the Extensive Reading courses, while the researchers of this study involved the learners that were still taking the Extensive Reading course when the study took place.

Two other researchers, Asgari and Mustapha (2011), conducted research on the types of vocabulary learning strategies used by ESL learners in University Putra Malaysia (UPM). The aim of the study was to examine the types of vocabulary learning strategies used by Malaysian ESL learners majoring in the Teaching English as a Second Language (TESL). The study used open-ended interviews, which were conducted individually with ten students at the Faculty of Education Studies in UPM. The study concluded that strategies such as learning a word through reading, using a monolingual dictionary, using various English language media, and applying new English words in the learners' daily conversation were the popular strategies and the learners liked using them. The study conducted by Asgari and Mustapha (2011) emphasized that reading was regarded only as activity.

In conclusion, reading is important in learning a foreign language. Through reading learners gain broader information, knowledge, and linguistic proficiency. Yet, many learners are not aware of the importance of reading. Therefore, learners need to get accustomed to reading. Extensive Reading course can be a good step to start with. Learners may choose reading materials they most like so that they enjoy the process of reading. Extensive Reading has positive advantages, one of them is to improve vocabulary mastery. Vocabulary itself is the key to learn a foreign language. Learners can use any ways to improve vocabulary mastery. The strategy they use is influential in mastering vocabulary. In short, learners need to choose the most effective strategy in the attempt to master vocabulary through Extensive Reading. Category of strategies by Schmitt (1997) is used in this study because they are more specific in terms of types and classification of strategy. 


\section{METHOD}

To find out what strategy Extensive Reading learners use in mastering vocabulary, this study uses the qualitative method, using questionnaire with opened-ended questions. Qualitative research is a scientific method of observation for a broad range of different approaches. They vary considerably in terms of focus, assumptions about the nature of knowledge and the role of the researcher (Astalin, 2013). The aim of the research is to identify what strategies Extensive Readinglearners of English Language Education Program (ELEP), Faculty of Language and Arts (FLA) of a private university in Central Java, Indonesiause in mastering vocabulary.

\section{Context of the Study}

This study was conducted at a private university in Central Java, Indonesia. The data were collected from the Extensive Reading course. In the weekly fourhour reading session in the Extensive Reading course learners are required to read story books from basic to intermediate level and make a summary. Based on curriculum, in Extensive Reading course, learners were expected to enhance fluency and accuracy in reading. Hence, the data were collected at the mid of first semester of 2019, when learners were well-informed about the learning goal of Extensive Reading course.

\section{Participants}

Participants of this study were all the Extensive Reading learners of batch 2019 taking the Extensive Reading course in first semester. Other learners of different year were not required to fill in the questionnaires. The reason why the researchers of this study involved only the learners of batch 2019 was that the Extensive Reading course was their first reading class. Technically they required strategies that suited their learning goal during the class. In total there were about 56 participants in 3 Extensive Reading classes. Questionnaires were given to participants after the class.

\section{Data Collection Instruments}

The study used qualitative research design to collect the data, using questionnaire with open-ended questions. Questionnaires were designed to obtain information about what strategy Extensive Reading learners use in mastering vocabulary. Zohrabi (2013) mentioned that questionnaires are unquestionably one of the primary sources of obtaining data in any research. This study used openedended questions to make learners express their ideas vividly. According to Singer and Couper (2017) opened-ended questionnaire may induce important insights, not only into respondents' substantive answers, but also into how they understand the questions we ask and arrive at an answer.

\section{Data Analysis Procedures}

From the first method, the data from opened-ended questions were analyzed to see the output of the strategy that have been used by the Extensive Reading 
learners in mastering vocabulary. Next, the data were organized according to the emerged themes, presented, and conclusions drawn.

\section{FINDINGS AND DISCUSSION}

In this section the research findings are discussed in order to answer the research question: What strategies did learners of Extensive Reading course use in mastering vocabulary? The results of the research were based on Schmitt (2000)'s theory. The categories are the determination strategy, social strategy, memory strategy, cognitive strategy and metacognitive strategy. The following graph shows the strategies that the learners use most to the strategies that the learners use the least.

Graph 1. Strategies Based on Schmitt's Theory

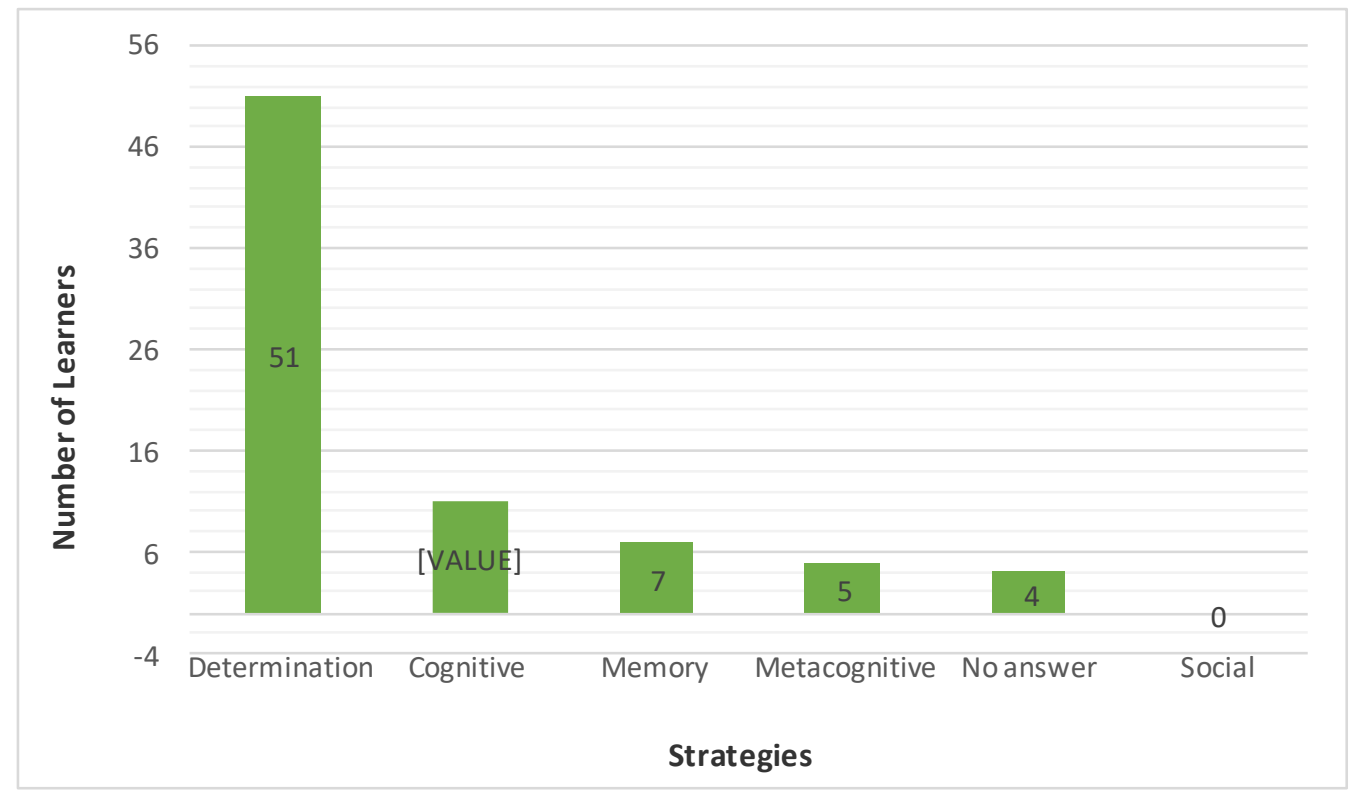

It can be inferred from the graph that most of the Extensive Reading course learners preferred using determination strategy in mastering vocabulary. It is accepted that the determination strategy is easily applicable and helpful for learners to improve their vocabulary mastery. Reading is one of the examples of the strategies. Learners would find new words from the passages they read. They would learn about the words by guessing the meanings from the contexts. If learners failed to understand the words by guessing the meanings from the contexts, they would consult their dictionaries for help. Javid (2013) mentioned in his study, most of the participants were university students in the Saudi EFL learner at Taif University. Javid reported that guessing the meanings of the words and using dictionaries were their main methods of the vocabulary learning strategy (VLS). The participants of the study consisted of 153 male and female Saudi EFL learners studying at Taif University in Saudi Arabia. The study was a cross sectional survey to gather information related to the frequency and 
effectiveness of VLS from a randomly selected sample drawn from the foreign languages department, Taif University.

The learners of ELEP also used what is called as cognitive strategy through which they would write down the new and difficult words they had found. This strategy helped the learners to make connections and reflection out of the reading passages. It is closely related with the cognitive strategy. Cognitive strategy deals with how to learn, how to remember and how to convey ideas reflexively and analytically. If learners have mastered the most appropriate learning strategy, they will be able to perform the self-learning, which is a process by which individuals take the initiative, with or without the assistance of others. The results of Rothkopf and Bisbicos' research as cited by Gagne (1977) showed that by utilizing the cognitive strategy, readers are capable of controlling their attention in understanding texts

Another strategy the learners applied was the memory strategy. Learners link their learning of the new words to mental processing by associating their existing or background knowledge with the new words (Schmitt, 2000). Using this strategy, learners will try to involve themselves in learning activities such as relating a word to a previous personal experience, associating the word with its coordinate, using semantic maps, figuring out word forms, grouping words together to study them, learning the spelling of words, saying new words aloud when studying and using a physical action when learning a word.

The last strategy the learners applied is the metacognitive strategy in which media are used. Learners of the Extensive Reading course used English Language media such as movies, news and songs to gain vocabulary. Actually, there are no activities like watching movies and listening to songs or news program, but some ER learners like to use this strategy to help them enrich their vocabularies. They mentioned that this strategy was attractive. By watching movies, listening to songs or news program learners might find new words that can be applied in the Extensive Reading class. None of the Extensive Reading course used the social strategy.

Although social strategy is popular among English learners, there were no learners out of 56 ER learners who used this strategy. Four respondents did not give any answers to the questionnaire.

\section{Determination Strategy}

Based on the questionnaire (question 5-6), fifty one (91.08\%) out of fifty six ER leaners used this strategy to improve their vocabulary mastery. They would guess the meaning of new words by comprehending the context. If the learners did not understand the meaning of words by guessing, they would use a dictionary to help them obtain more comprehensive meaning of words. Not all of the learners liked guessing the meaning of words by reading the context. They would promptly open dictionaries when they found difficult words to understand. Twenty four learners $(42.86 \%)$ reported that dictionaries were significantly helpful to improve their vocabulary mastery, that is, to learn more new words. They were not certain about the actual meanings of the words only by guessing them from the context. As Schmitt (2000) said in his theory, the determination 
strategy indeed helps learners learn individually without assistance of the peers. These are two ways learners can do. First, they can guess the meaning of a difficult word through the context, analyzing part of speech, affixes, roots, and available pictures or gestures. And second, they can consult their dictionaries for help. The Graph 2 shows the kinds of strategies with their parts, which were used by learners.

\section{Graph 2. The Use of Determination Strategy}

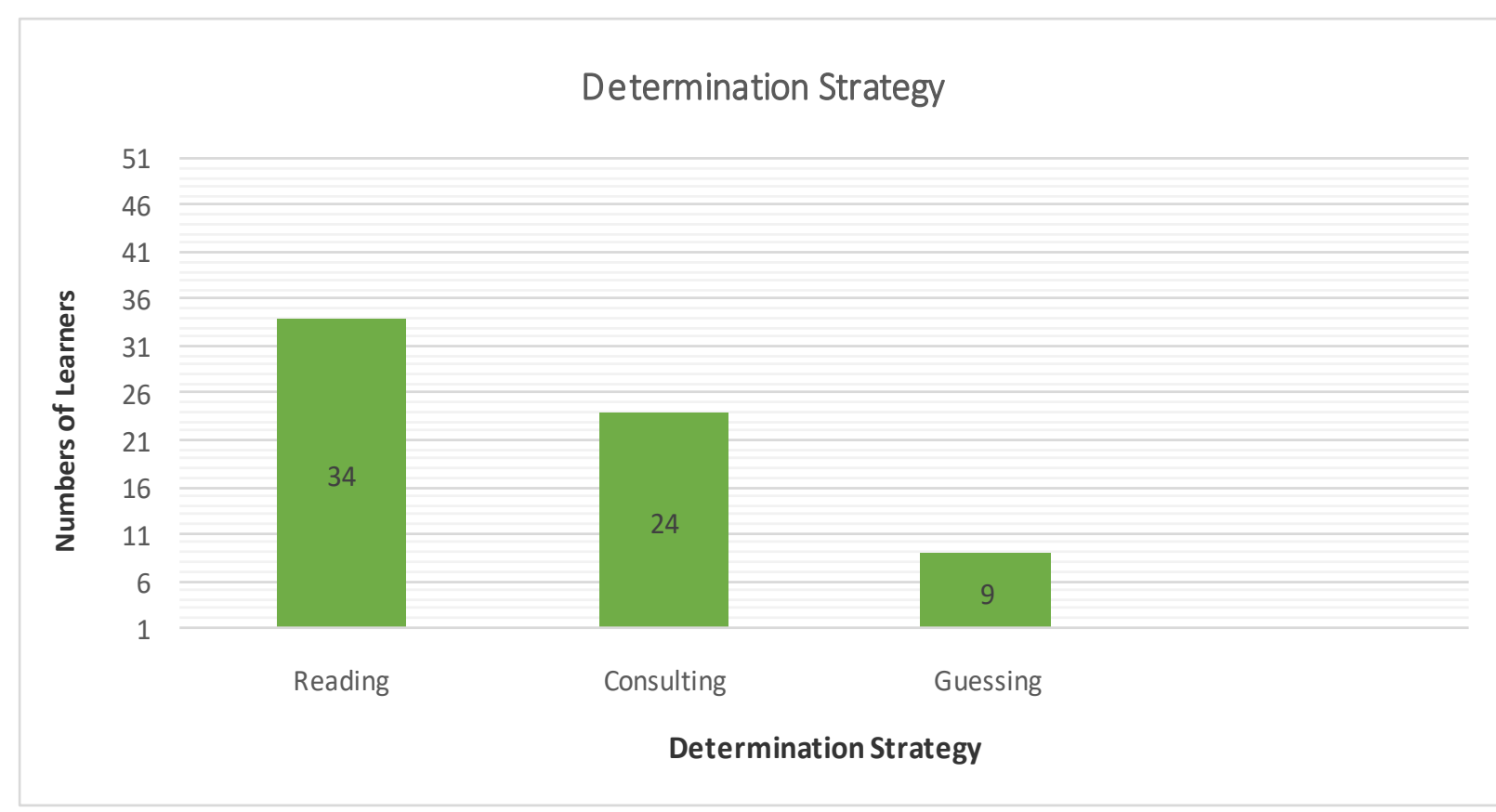

The above graph shows that the ER learners preferred reading books to gain more vocabularies. Thirty four out of fifty-one (91.08\%) ER learners used the determination strategy by reading. As many as twenty four out of fifty-one ER learners preferred using dictionaries to help them understand the meaning of new difficult words, nine learners preferred guessing the meaning of new words based on context.

Based on the findings of the research through the questionnaire, the researchers classified the determination strategy into three parts. The first one is reading. Learners are expected to improve vocabulary mastery by reading books of various genres. Learners of the ER course mentioned that they also read books of other genres, so that they would get more vocabulary. They would read books with higher level of difficulties in terms of vocabulary mastery. By reading such books the learners might have obtained more new vocabularies. Based on the questionnaire (question 5-6), thirty-four (60.72\%) learners reported that reading books of various genres and of higher levels of difficulty was indeed very helpful to improve their vocabulary mastery. They made a summary out of the books they had read and they seemed to be more confident when they made presentation 
before class. These were made possible due to their preparedness after the mastery of new words. These reasons were also supported by several learners' opinions.

\section{Excerpt 1}

"By reading a lot. In this Extensive Reading class, learners are required to read a lot in such a way that they can naturally enrich their vocabulary." (Student C, Answer on Question 5)

The other method is called consulting. The learners could use dictionaries to help them understand the meaning of words. The dictionaries were used when learners found difficulties in guessing the meaning of words by reading the context only. Twenty-four $(42.86 \%)$ learners reported that using dictionaries was more practical and easier than understanding words from the context. It was their first time reading the books with levels of difficulty and making summaries. Learners found a number of difficult words and hence they needed dictionaries to find out the meanings.

\section{Excerpt 2}

"Guessing is quite helpful to me. We are challenged to estimate the closest meaning of every word found in the reading passage." (Student U, Answer on Question 6)

The last method used by the ER learners was guessing. Through this method, learners tried to comprehend the meaning of words by reading the context, analyzing part of speech, affixes, roots, and available pictures or gestures.

\section{Excerpt 3}

"When I read books, I usually find new words. I note them down and consult my dictionary to find out the meanings of those words. In this way I can enrich my vocabulary and improve my skill in the reading comprehension." (Student D, Answer on Question 5)

Eight (14.29\%) learners reported that they tried to guess the meaning of words from the context in the books. They did not use dictionaries to consult, because they found it easier to learn new words from the context during their perusal.

\section{Cognitive Strategy}

Cognitive strategy involves students in the learning processes, teaching them to use their brains more effectively to make connections when learning new things. It consists of verbal repetition, written repetition, word list, putting English labels on physical object and keeping vocabulary notebook (Schmitt, 2000). 
Cognitive strategy may include a number of activities taking place in the brain while the linguistic tasks are at hand. When using the cognitive strategy in learning a language, learners use their mental process (Pratama, Setiyadi and Flora, 2015).

Eleven (19.65\%) ER learners preferred using the cognitive strategy to improve their vocabulary mastery. They found the cognitive strategy more helpful to learn and memorize new words along with the meanings and it enabled them to understand the contents of the passages easily.

\section{Graph 3. The Use of Cognitive Strategy}

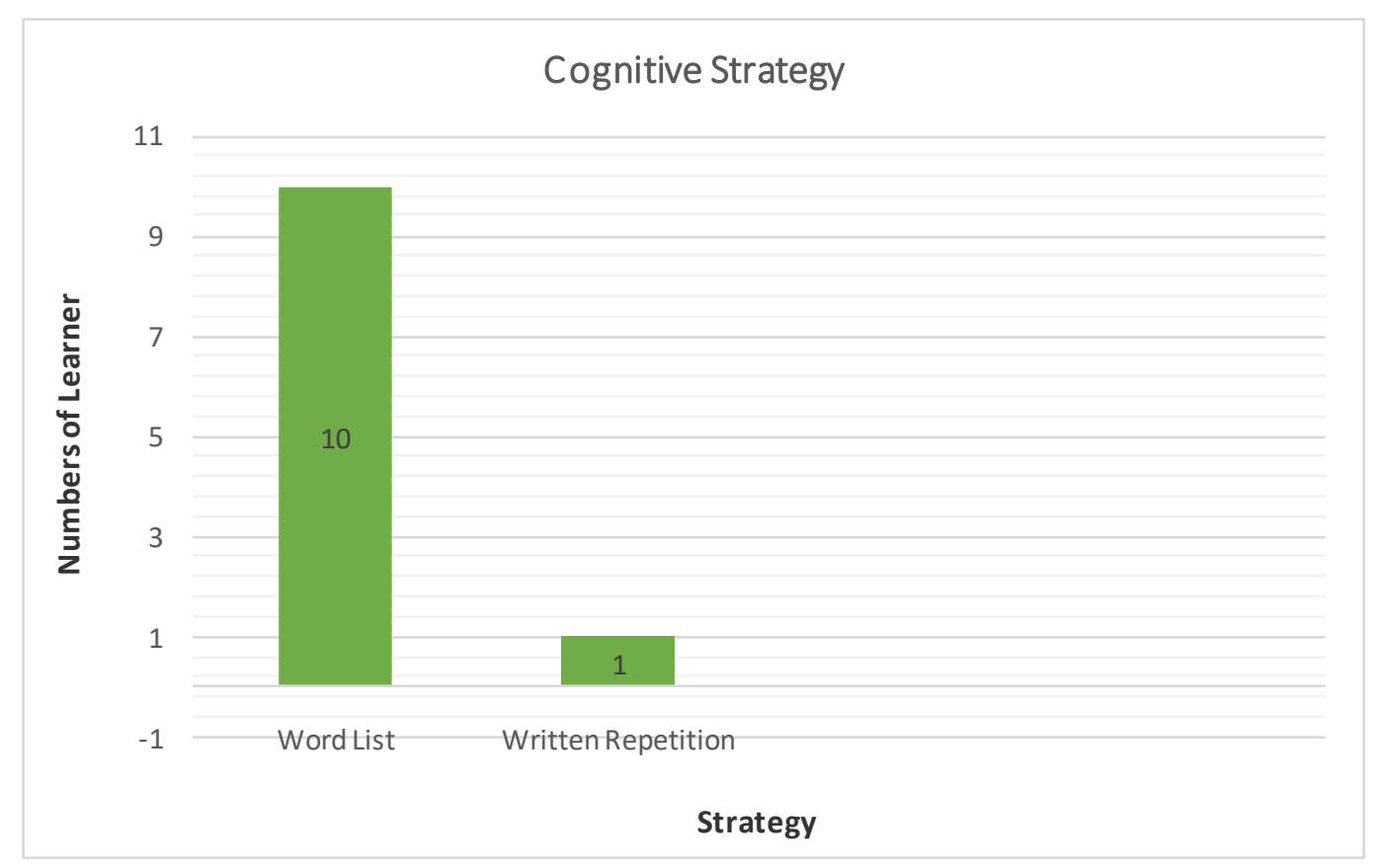

From the above graph, it can be seen that two kinds of cognitive strategies are used by eleven ER learners, i.e. written repetition and word list. There are two methods of cognitive strategy those eleven learners use: written repetition and word list. Ten learners $(17.86 \%)$ choose to rewrite the new words along with the meanings they find from passages while the other (one $(1.79 \%)$ choose to write in paragraph.

\section{Excerpt 4}

"Whenever I find new words and the meanings are unfamiliar, I prompt to write them down on my notebook, consult my dictionary to find the meanings, then I memorize them. This indeed helps me enrich my vocabulary and improve my proficiency in the reading comprehension." (Student O, Answer on Question 5) 
One learner preferred writing in paragraph and mentioned that it was an easy and appropriate method to master vocabulary quite rapidly.

\section{Excerpt 5}

"I have my own strategy to enrich my vocabulary during my class of ER. I would read some passages, find some difficult words, consult my dictionary to find the meanings and I try to make sentences using those words. I repeat this way of learning." (Student R, Answer on Question 5)

Those methods helped them to memorize new words. They mentioned that rewriting the difficult words enabled them to memorize the words and the meanings more easily and therefore they would comprehend the passages more vividly. They kept with them all the necessary notes containing lists of new words with the meanings.

\section{Memory Strategy}

The third strategy used by the ER learners is the memory strategy, in which the learners are required to link their learning of new words to mental processing by associating their existing or background knowledge with the new words (Schmidt 2000). Memory strategies have also been defined as mental or behavioral activities that achieve cognitive purposes and are effort-consuming, potentially conscious and controllable (Flavell et al 1993). Using this strategy learners would try to engage themselves in learning activities such as connecting a word to a previous personal experience, associating the word with its coordinate, using semantic maps, imaging word forms, grouping words together to study them, learning the spelling of words, saying new words aloud when studying and using a physical action when learning a word. The following data show the using of the memory strategy:

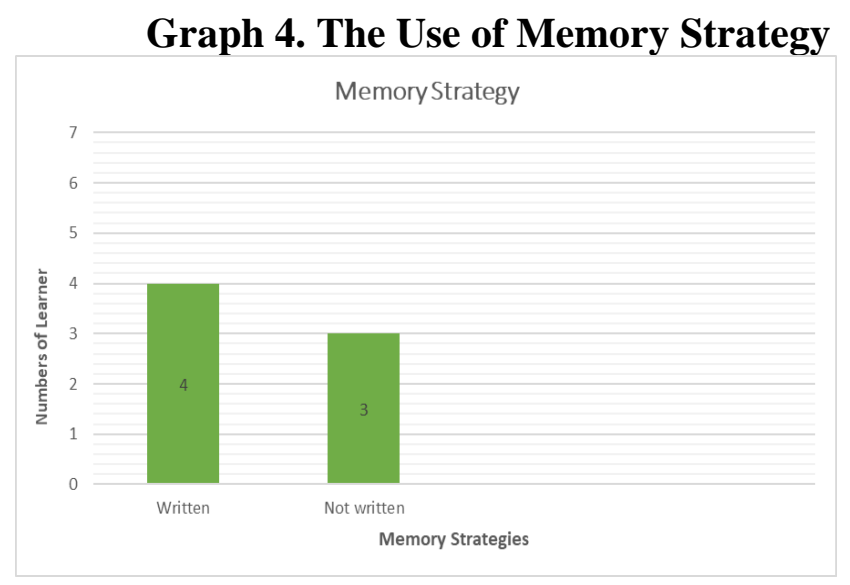

Seven out of fifty-six ER learners $(12.5 \%)$ used the memory strategy to improve their vocabulary mastery. Four of them (7.15\%) wrote down new words 
along with the meanings and would memorize them. Seperti yang dikatakanoleh student $\mathrm{M}$ dalam questionnaire.

\section{Excerpt 6}

"By reading books of any genres from level 1 to 5 . Then I try to find some difficult words, try to find the meanings of the words using dictionary. Then I try to memorize the words along with the meanings." (Student M, Answer on Question 5)

The rest (three learners $(5.34 \%)$ preferred memorizing new words along with the meanings without writing them down.

\section{Excerpt 7}

"I Find some new words, use the dictionary to help me find the meanings or definition. Then I pronounce the English words and the meanings in Indonesian language, I do this five times. This is the way I memorize words. The words I have learned from a book or an article occasionally emerge in other books or articles so I have less difficulties to understand all the contexts." (Student A, Answer on Question 5)

Learners that did not note new words down nor make word list would try to memorize the meanings of the new words they found directly. They would read by heart all the words over and over so that they could linger or remain in their mind as permanent memory.

\section{Metacognitive Strategy}

The fourth strategy that most ER learners used was the metacognitive strategy, a strategy that helps learners in determining appropriate VLSs using English language media (songs, movies, news, etc.). This strategy requires that the learners use space of word practice, test themselves with word tests, skip or pass new word, and continue to study new word over time (Schmitt,2000). It helps learners to specify appropriate vocabulary learning strategies for learning new words. The goal of the metacognitive strategy is to teach learners to become purposeful, effective and independent learners. Learners using this strategy are capable of making plans for their studies (Pratama, Setiyadi and Flora). The learners used these strategies out of their initiative because it is attracting and not boring. By watching movies, listening to songs or news program learners might find new words that can be applied in the Extensive Reading class. The following table shows the usage of the metacognitive strategy in the Extensive Reading course. 
Graph 5. The Use of Metacognitive Strategy

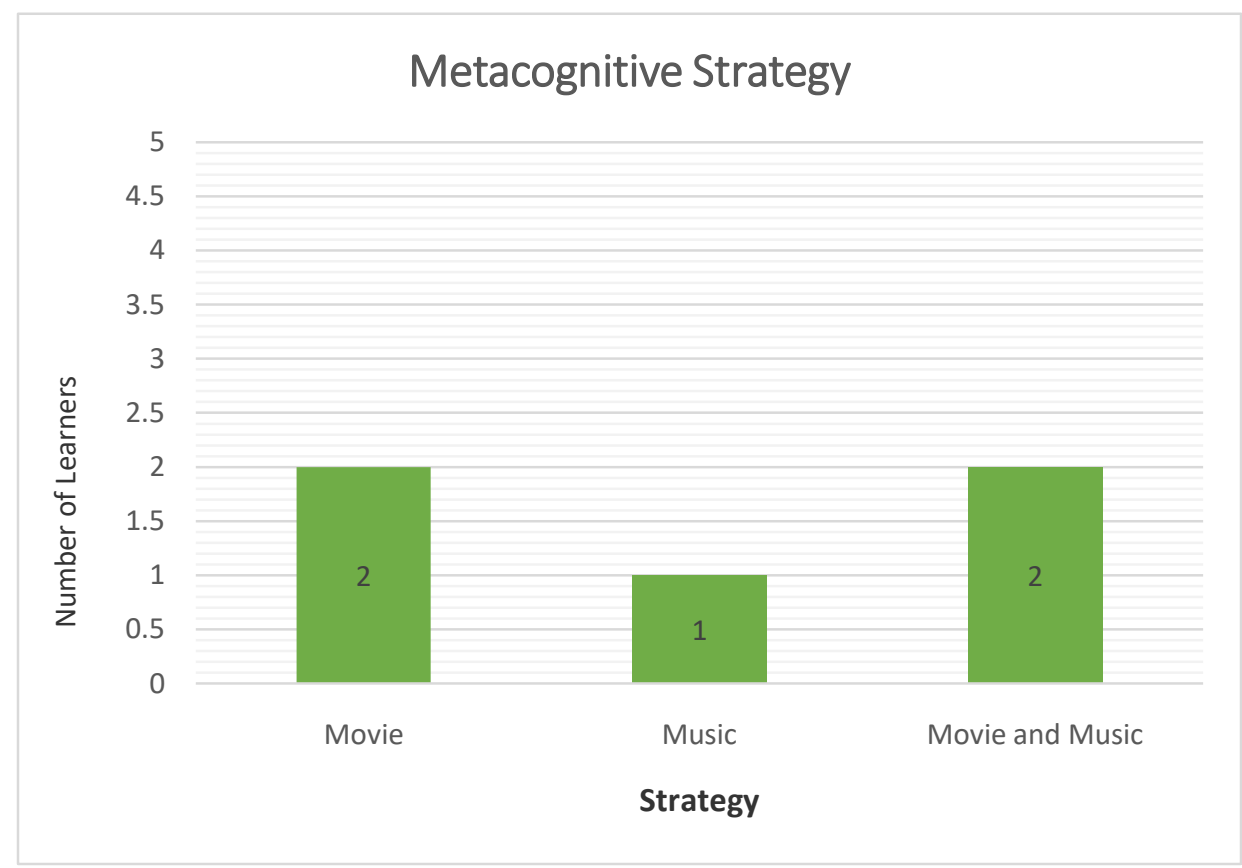

Five out of fifty-six ER learners $(8.93 \%)$ chose to use metacognitive strategy to improve their vocabulary mastery. Two learners $(3.58 \%)$ reported that they succeeded in learning new words through watching English movies. They found many new words from the dialogues in movies. Then they noted down the new words and learn the meanings.

\section{Excerpt 8}

"Of course. We would find more new words and it might help us speak more fluently.”) (Student E, Answer on Question 6)

Only one learner preferred listening to English songs in his attempt to improve his vocabulary mastery. He focused on the lyrics of the songs and he would pick up some new words, note them down, and learn about the meanings. He also mentioned that listening to music made him relaxed and focused. In this way he could improve his vocabulary mastery. Below was the opinion from one of the ER learners.

\section{Excerpt 9}

"Yes, of course. listening to English songs and reading books certainly help me improve my vocabulary mastery especially during my taking the ER class." (Student H, Answer on Question 6)

The other two learners (3.58\%) chose to use both English movies and songs to learn new words. They found watching movies and listening to music and 
songs much more challenging yet relaxing in such a way that made them enthusiastic in learning new words. In this way they memorized the new words and their meanings more easily.

\section{Excerpt 10}

"Those media indeed help me improve my vocabulary mastery. They work. I can easily pace my way in the ER class, passed all the quizzes." (Student J, Answer on Question 6)

The learners found watching movies and listening to music and songs more challenging and relaxing in such a way that it made them enthusiastic in learning new words. In this way they memorized the new words and their meanings more easily.

\section{Social Strategy}

The last strategy used in this research is the social strategy. According to Schmitt (2000), social strategy is referred to as a strategy used by learners when learning new words through interaction with others. Based on the responses to the questionnaire, none of the 56 ER learners used the social strategy. All of them preferred learning individually and using media such as videos, movies, and songs to learning with their peers.

They tend to learn individually rather than study in groups. Moreover, in this course, they were required to read much in order to pass the Extensive Reading course. In fact, through this strategy, learners are advised to get involved in interaction with their peers and the strategy assists them to learn from each other, such as observing the classmates and asking the teacher about word meanings and the semantics.As stated by Oxford (1990), social strategies are those that involve other individuals in the learning process and refer to cooperation with peers, questioning, asking for correction, and give feedback to each other. Learners can have a discussion with their peers, help the other friends, giving praise to other, consult the teacher and a learner may ask another individual for feedback about his / her reading responses. In fact, none of the participants in this study mentioned and used the social strategy in their answers in the questionnaire.

The different part of this study from that of Dwitama (2015) is the participants. Dwitama focused on the participants that had passed the ER class, while the researchers of this study focused on the ER learners that were still taking the ER class. However, Dwitama's research and this study showed the same results, most of the ER learners liked using the determination strategy to master the vocabulary. Very few of them used the social strategy.

Thus, the different part of this study from the one conducted by Asgari and Mustapa (2011) is the purpose of the readingand the context of ESL. This study puts reading in the main frame of learning and in the ER reading is a required subject, whereby English is the main language (EFL).Asgari and Mustapa (2011) use the Schmitt's (1997) theory as their basic line in their research. In Asgari and Mustapa's study, reading is not the focus of the study. It is regarded only as an 
activity. Asgari and Mustapaused Schmitt's (1997) theory. On the contrary, this study uses the Schmitt's theory (2000). This study shows the same result concerning the strategy; all participants use the determination strategy, none use the social strategy. In the study by Asgari and Mustapa (2011), the determination strategy is referred to as a strategy that involves guessing, consulting and reading.

\section{CONCLUSION AND SUGGESTION}

Extensive Reading (ER) was a compulsory course and a prerequisite for a student before taking another reading class. This is in accordance with the regulations of English Language Education Program (ELEP), at the private university where this study took place. In this course learners are suggested to apply strategies to improve vocabulary mastery in order that they will be able to comprehend the reading passage effectively and quickly. Hence, this study was aimed at finding out what strategies the ER learners of the ELEP used. The applications of those strategies were classified into five based on Schmitt (2000) categories. The research question in this study is what the most appropriate strategy the Extensive Reading learners used and apply in their attempt to master the vocabulary.

Based on the answers of the distributed questionnaires, it can be concluded that the determination strategy was the most preferable strategy to most of the ER learners (51 out of 56 participants) in their efforts to improve vocabulary mastery. The result of the study also showed the following facts. As many as eleven learners used the cognitive strategy. Seven used the memory strategy and five used the metacognitive strategy. None of the ER learners used the social strategy and surprisingly there were four learners did not give answers to the questionnaire (question 5 and 6). The application of learning strategy varies due to several factors, personal and experiential factor in efforts to improve vocabulary mastery and reading comprehension. Each learner had his own strategy that suited his learning purpose.

The result of this study is expected to help widen the ER learners' knowledge about the learning strategies concerning the vocabulary mastery. Conducting research on vocabulary learning strategies through reading is considered not only interesting but also beneficial to widen the scope of study and the perspectives in future research. It is strongly recommended for future researchers dig deeper about it. Overall, it is highly expected that the findings on this study can be beneficial for the English learners to enrich their knowledge on the strategies of vocabulary learning on reading.

\section{REFERENCES}

Alqahtani, M. (2015). The importance of vocabulary in language learning and how to be taught. International Journal of Teaching and Education 3(3), 21-34. doi:10.20472/TE.2015.3.3.002 
Arndt, H, L., \&Woore, R. (2018). Vocabulary learning from watching YouTube videos and reading blog posts. Language Learning \& Technology22(1), 124-142 doi:10125/44660

Asgari, M., \& Mustapha, G, B. (2011). The type of vocabulary learning strategies used by ESL students in University Putra Malaysia. English Language Teaching 4(2) 84-90. doi:10.5539/elt.v4n2p84

Astalin, P, K. Qualitative research designs: a conceptual framework. International Journal of Social Science \& Interdisciplinary Research 2(1), 118-124. Retrieved from https://pdfs.semanticscholar.org/baa7/c8f5577b0b1798b5e9f559f5cbae32b $\underline{\text { f1a36.pdf }}$

Cambridge University Press. (2018). Extensive reading in ELT: Why and how? Retrieved from https://languageresearch.cambridge.org/images/Language_Research/Camb ridgePapers/CambridgePapersinELT_ExtensiveReading_2017_ONLINE.p $\underline{\mathrm{df}}$

Day, R, R., \& Bamford, J. (1998). Extensive reading in the second language classroom. New York: Cambridge University Press.

Dwitama, S, D. (2015). Vocabulary learning strategies used by FLL students in extensive reading class (SarjanaPendidikan Degree, Universitas Kristen SatyaWacana) Retrieved from http://repository.uksw.edu/bitstream/123456789/9851/2/T1_112008074_F ull\%20text.pdf

Easterbrook, R, M. (2013). The process of vocabulary learning: vocabulary learning strategies and beliefs about language and language learning (Doctor of Philosophy in Education, The University of Canberra) Retrieved from http://www.canberra.edu.au/researchrepository/file/3384527a-1649-4e50b61f-32a9979276e6/1/introductory_pages.pdf

Elley, W, B. (1992). How in the world do students read? The IEA study of reading literacy. American Journal of Educational Research 3(2), 126136. doi:10.12691/education-3-2-4

Flavell, J. H. (1993). Young children's understanding of thinking and consciousness. Current Directions in Psychological Science 2(2), 40-43. doi: 10.1111/1467-8721.ep10770682

Gagne, R. M. (1977). The condition of learning. 3rd Edition, Holt, Rinehart, and Winston, New York.

He, Y. (2010). A study of 12 vocabulary learning strategies (Kristianstad University, The School of Teacher Education English IV). Retrieved from http://www.divaportal.org/smash/get/diva2:326994/fulltext01.pdf 
Huettig, F., \& Pickering, M, J. Literacy advantages beyond reading: Prediction of spoken language. Trends in Cognitive Sciences 23(6), 464-475. doi:10.1016/j.tics.2019.03.008

International Literacy Association. (2019). Literacy Leadership Brief: Creating passionate readers through independent reading. Retrieved from https://www.literacyworldwide.org/docs/default-source/where-westand/ila-creating-passionate-readers-through-independent-reading.pdf

Javid, C, Z. (2014). A comparative determination of vocabulary learning strategies of Saudi EFL learners. Research Journal of Recent Sciences3(12), 32-41.

Lin, D, T. (2016) Investigating guided extensive reading and vocabulary knowledge performance among remedial ESL learners in a public university in Malaysia (Doctor of Philosophy, UniversitiSains Malaysia). Retrieved from https://core.ac.uk/download/pdf/78388981.pdf

Oxfam. (2019). Conducting semi-structured interviews. Retrieved from https://itp.nyu.edu/classes/fungus/interview_technique/conductingIntervie ws.pdf

Pratama, M. F., Setiyadi, A. B., \& Flora, F. (2015). The influence of language learning strategies towards reading comprehension. U-JET4(6), 1-11.

Schmitt, N. (2000). Vocabulary in Language Teaching. Cambridge University Press, Cambridge.

Singer, E., \& Couper, M. P. (2017). Some Methodological Uses of Responses to Open Questions and Other Verbatim Comments in Quantitative Surveys. Methods, data, analyses: a journal for quantitative methods and survey methodology (mda), 11(2), 115-134. doi:10.12758/mda

Smith, F. (1978). Understanding reading: a psycholinguistic analysis of reading and learning to read $\left(2^{\text {nd }} e d\right)$. New York: Holt, Rinehart and Winston.

Sonbul, S., \& Schmitt, N. (2010). Direct teaching of vocabulary after reading: is it worth the effort?. ELT Journal 63(4),253-60. doi:10.1093/elt/ccp059

Teng, F. (2015). The effectiveness of Extensive Reading on EFL learners' vocabulary learning: Incidental versus intentional learning. Brazilian English Language Teaching Journal 6(1), 66-80. doi:10.15448/21783640.2015.1.20033

Zohrabi, M. (2013). Mixed method research: Instruments, validity, reliability and reporting findings. Academi Publisher 3(2), 254-262. doi:10.4304/tpls.3.2.254-262 